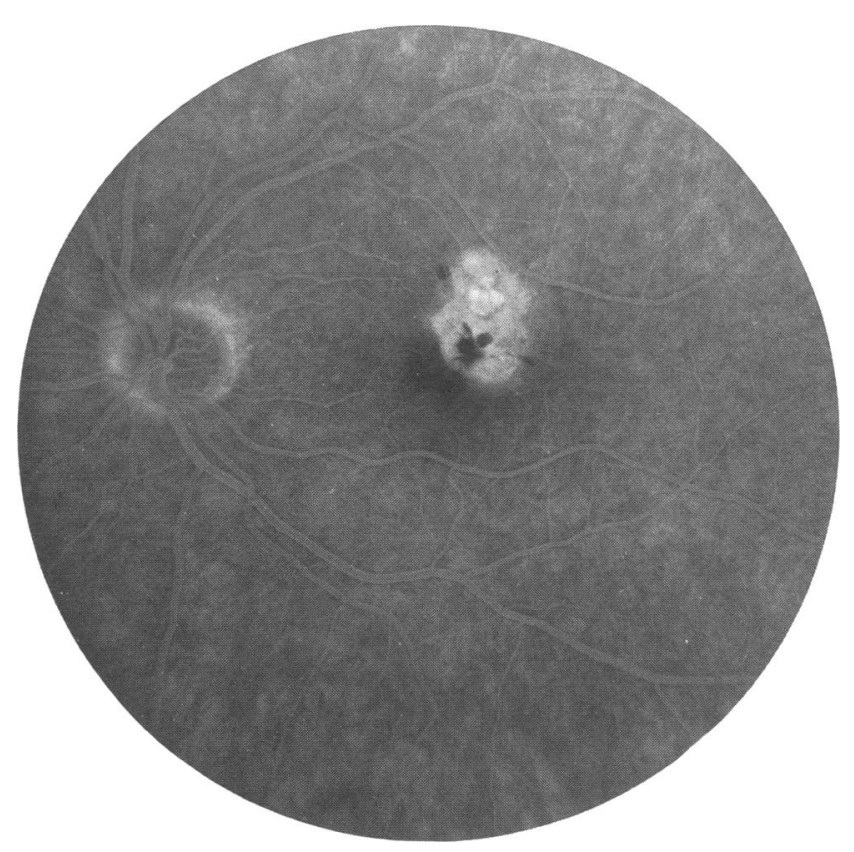

Figure 3. Late phase fluorescein angiogram, leakage of fluorescein from a subretinal neovascular membrane

American study of the Tae Kwon Do national championships, found that $52 \%$ of all injuries involved the head and neck region. ${ }^{2}$ During the first European knockdown karate championships $53 \%$ of the competitors were injured and $30 \%$ of these injuries were to the head and neck. ${ }^{3}$ These previous reports suggest that under tournament conditions the distinction between those martial arts disciplines that permit full contact and those that do not becomes blurred. This is consistent with previous work that has found that injuries tend to be more severe under tournament conditions than when training. ${ }^{4}$

There have been several recommendations aimed at reducing both the rate and the severity of injury. The presence of trained ringside physicians for early diagnosis and treatment is usually recommended ${ }^{2}$ but severe traumatic maculopathies, such as described here, may result from a single blow, and their complications may not be treatable even if there is early diagnosis. The use of protective padding of the fists, forearms, shins, and feet has been recommended, ${ }^{2}$ but their use did not prevent injury in this case. Additionally, a previous biomechanical study has shown that target acceleration is not significantly affected by the use of such padding. ${ }^{5}$ Floor padding has also been recommended to prevent injury to a contestant when hitting the floor. ${ }^{6}$ Lack of such padding may well have been a factor in the prolonged unconsciousness sustained in the case we describe. However, the most likely way of reducing these types of injuries is to exclude the head as a target area, as others have already suggested, ${ }^{2}$ although this case proves that even this would not be infallible.

Martial arts are an increasingly popular sporting pastime, with a proliferation of tournaments over the years. It is apparent from published reports and the case we describe here that injuries to karatekas can be both common and severe. The medical profession should continue to lead the debate on sporting injuries and remind sporting governing bodies both of the continuing levels of injury and of ways to make sport safer.

\section{Acknowledgements}

We would like to thank Mr RF Walters for permission to report on his patient.

\section{References}

1 McLatchie GR. Analysis of karate injuries sustained in 295 contests. Injury 1976; 8: 132-34.

2 Oler M, Tomson W, Pepe H, Yoon D, Branoff R, Branch J. Morbidity and mortality in the martial arts: a warning. J Trauma 1991; 31: 251-53.

3 McLatchie GR, Davies JE, Caulley JH. Injuries in Karate-a case for medical control. J Trauma 1980; 20: 956-58.

4 Birrer RB, Birrer CD. Unreported injuries in the martial arts. $\mathrm{Br} J$ Sports Med 1993; 17: 131-33.

5 Schwartz ML, Hudson AR, Fernie GR, Hayashi K, Coleclough AA. Biomechanical study of full-contact karate contrasted with boxing. J Neurosurg 1986; 64: 248-52.

6 McLatchie G. Karate and karate injuries. Br J Sports Med 1981; 15 : $84-6$.

\title{
Spontaneous rupture of the anterior cruciate ligament after anabolic steroids
}

\author{
Brian J C Freeman and Guy D Rooker
}

Department of Orthopaedic Surgery, Cheltenham General Hospital, Cheltenham, Gloucestershire, UK

\begin{abstract}
Anabolic steroids remain popular among body builders and power athletes despite numerous warnings about their side effects. A case of spontaneous rupture of the anterior cruciate ligament is reported in a bodybuilder taking steroids. While there are many published reports of tendon rupture associated with steroid intake, the authors could
\end{abstract}

Address for correspondence: Brian J C Freeman FRCS, 11 The Hornbeams, Malborough Drive, Frenchay, Bristol BS16 1PW, UK. find no report relating to ligament disruption. (Br J Sports Med 1995; 29 : 274-275)

Keywords: anterior cruciate ligament, spontaneous rupture, anabolic steroids

\section{Case report}

A twenty two year old body builder presented one week after an apparently trivial injury to his right knee. 
He had stumbled over two steps and developed an effusion. His knee had given way several times since the injury. On examination a small effusion was still present. Both collateral ligaments were stable. The anterior drawer test was negative but Lachmann's test was positive. On direct questioning he admitted taking anabolic steroids. He had just completed 'an eight week course' of oxymethalone, taking $50 \mathrm{mg}$ four times a day during this period.

Six weeks later he was admitted for an arthroscopy. On examination under anaesthetic both collaterals were intact, and his anterior drawer and Lachmann's test were both positive on this occasion. Arthroscopy showed a complete rupture of the anterior cruciate ligament with intercondylar synovitis. The patient was informed of the diagnosis. He was treated conservatively with physiotherapy. At follow up one year later the patient had changed his lifestyle significantly, he denied any further anabolic steroid misuse. He complained occasionally of giving way but was not keen to progress to an autologous anterior cruciate ligament repair.

\section{Discussion}

Anabolic steroid abuse is now receiving greater media attention. Perry et al. ${ }^{1}$ have shown prevalence rates of over $35 \%$ in certain gymnasia. Korkia and Stimson ${ }^{2}$ have found that $9 \%$ of men and $2 \%$ of women in their particular study cohort have used anabolic steroids at some time. With the widespread use of such drugs the incidence of complications is expected to increase.

There are numerous papers linking tendon rupture with misuse of anabolic steroids. For example Hill et al. ${ }^{3}$ describe a spontaneous rupture of the quadriceps tendon in an athlete following such drug abuse, Kramhoft and Solgaard ${ }^{4}$ report on the rupture of the extensor pollicis longus tendon, and both Bach et al. ${ }^{5}$ and Herrick and Herrick ${ }^{6}$ independently report triceps rupture in weight lifters using steroids.

There are many theories about the mechanism of rupture. The increase in muscle power observed in some individuals is not matched by an increase in the tendon strength, thereby predisposing to rupture. Among lifters the two structures that tend to rupture are the biceps tendon and the quadriceps. Others have suggested that steroid induced aggression may cause individuals to overtrain. Normal signals telling the athlete to stop maybe overridden by the steroids, resulting in injury. Finally, Laseter and Russell ${ }^{7}$ suggest that anabolic steroid use combined with exercise may lead to dysplasia of collagen fibrils, which can decrease the tensile strength of the tendon. Wood et al. ${ }^{8}$ have shown changes in crimp morphology of rat tendons exposed to exercise and anabolic steroids. These changes may alter the rupturing strain of tendons.

We believe this case report supports the theory that the combination of exercise and anabolic steroids results in human connective tissue disruption. It is the first case report linking ligament rupture with systemic use of anabolic steroids.

\section{Acknowledgements}

The authors would like to thank Michele Verroken of the Sports Council and Lesley Harrison of the National Sports Medicine Institute.

\section{References}

1 Perry HM, Wright D, Littlepage BNC. Dying to be big: a review of anabolic steroids. Br J Sports Med 1992; 26: 259-61.

2 Korkia P, Stimson GV. Anabolic steroid use in Great Britain. London The Centre for Research on Drugs and Health Behaviour, 1993.

3 Hill JA, Suker JR, Sachs K, Brigham C. The athletic polydrug abuse phenomenon. A case report. Am J Sports Med 1983; 11: 269-71.

4 Kramhoft M, Solgaard S. Spontaneous rupture of the extensor pollicis longus tendon after anabolic steroids. J Hand Surg 1986; 11 87.

5 Bach BR, Warren RF, Wickiewicz TL. Triceps rupture: a case report and literature review. Am J Sports Med 1987; 15 : 285-9.

6 Herrick RT, Herrick S. Ruptured triceps in a powerlifter presenting as a cubital tunnel syndrome: a case report. Am J Sports Med 1987, 15 : $514-6$.

7 Laseter JT, Russell JA. Anabolic steroid-induced tendon pathology: a review of the literature. Med Sci Sports Exerc 1991; 23: 1-3.

8 Wood TO, Cooke PH, Goodship AE. The effect of exercise and anabolic steroids on the mechanical properties and crimp morphology of the rat tendon. Am J Sports Med 1988; 16: 153-8.

\title{
Traumatic arteriovenous fistula of the superficial temporal vessels: a case for protective headgear when playing squash?
}

\author{
Simon R Stubington and Keith M Rigg \\ Department of Surgery, Nottingham City Hospital, Hucknall Road, Nottingham, NG5 IPB, UK
}

A 35 year old semiprofessional squash player developed the symptoms and signs of an arteriovenous fistula of the left superficial temporal vessels after a squash ball injury. This was sufficiently symptomatic to halt his intensive

Address for correspondence: Mr S R Stubington FRCS, Department of Surgery, Nottingham City Hospital, Hucknall Road, Nottingham NG5 1PB, UK. training programme and required exploration, ligation and excision. Although a rare injury from any cause this would have been prevented by protective headgear.

(Br J Sports Med 1995; 29: 276-277)

Keywords : arteriovenous fistula, temporal arteries, racquet sports, head protective devices 